\title{
Cibercultura
}

\section{A organização da indústria fonográfica brasileira nas redes digitais: concentração sem centralização das empresas eletrônicas fonográficas'}

The organization of the Brazilian record industry in the digital networks: concentration without centralization of the phonographic e-companies

\section{LEONARDO DE MARCHI}

Doutor em Comunicação e Cultura pela Universidade Federal do Rio de Janeiro - UFRJ. Pós-Doutorando da FAPESP.

Pesquisador no CTR da ECA-USP.

<leonardodemarchi@gmail.com>

\section{RESUMO}

O objetivo deste artigo é analisar a organização da indústria fonográfica brasileira no mercado digital. Adotando uma abordagem político-cultural dos mercados, buscase demonstrar que as relações de poder que formam o mercado de discos físicos se reproduzem nas redes digitais. A hipótese é que o poder de dispor dos catálogos controlados por gravadoras e artistas torna-se um vetor crítico para o desenvolvimento das empresas eletrônicas e que, a partir de seu controle, estabelece-se uma divisão do trabalho entre si. A partir da observação de páginas na internet relacionadas à música, a análise dos dados obtidos leva a concluir que a

\section{ABSTRACT}

The article analyzes the organization of the Brazilian record industry in digital market by observing the electronic companies. Adopting a political-cultural approach to the markets, it seeks to demonstrate that the power relations that make up the market for physical discs are reproduced in the digital environment. The hypothesis is that the power to dispose of music catalogs controlled by record companies and artists becomes a critical vector to the development of electronic business and, from their control, establishes a division of labor among those companies. Observing and comparing websites related to music, the analysis leads to 
partilha desigual dos catálogos entre empresas eletrônicas acarreta uma concentração na distribuição dos fonogramas digitais sem que haja uma centralização da produção, criando uma concentração sem centralização do mercado fonográfico digital.

Palavras-chave: Economia da cultura. Mercado de conteúdos digitais. Indústria fonográfica. the conclusion that the unequal sharing of catalogs among electronic companies creates a concentration of the distribution of digital phonograms without a centralization of music production, creating a "concentration without centralization" of the digital record market.

Keywords: Culture economy. Digital content market. Record industry.

$\mathrm{O}$ primeiros anos da digitalização dos produtos e dos canais de distribuição das indústrias culturais foram marcados por diversas especulações sobre o futuro dos mercados de cultura. Chegou-se a afirmar que as tecnologias digitais da comunicação reconfigurariam radicalmente tais mercados, uma vez que permitiam a artistas e público negociarem diretamente. Isso implicaria a perda do poder de regulação das grandes empresas de comunicação e cultura, uma vez que seu papel de mediadores teria se perdido. É interessante notar que a indústria fonográfica foi tomada como exemplo desse fenômeno. Diante de novas práticas de consumo de fonogramas pelas redes digitais, como o compartilhamento gratuito de fonogramas digitais pela internet, e da incapacidade das gravadoras de lidarem com tais transformações, parecia ser o fim do controle dessas corporações sobre a produção e o consumo de música e a conseguinte criação de um livre-mercado de bens culturais.

Porém, a análise do desenvolvimento do mercado de fonogramas nas redes digitais lança dúvidas sobre tal interpretação. Uma observação atenta revela que esse comércio se organiza em torno de empresas eletrônicas especializadas em conectar produtores de conteúdos digitais (artistas e/ou gravadoras) a diferentes tipos de consumidores (indivíduos e/ou empresas), a partir da oferta de diferentes serviços. A oferta de serviços 
está prioritariamente relacionada aos catálogos oferecidos. Como não produzem os conteúdos com que trabalham, as empresas eletrônicas necessitam dos direitos sobre esses bens para sua comercialização. Logo, elas têm a negociar com as empresas de cultura e/ou artistas, os quais selecionam com quais intermediários preferem trabalhar. Isso gera uma gradação no acesso aos conteúdos digitais, permitindo o estabelecimento de uma diferenciação entre as empresas eletrônicas e novas relações de poder entre os tradicionais agentes da indústria fonográfica e os agentes do mercado de conteúdos digitais.

O objetivo deste artigo é entender a organização da indústria fonográfica brasileira nas redes digitais a partir da análise da diferenciação de catálogos e serviços das empresas eletrônicas fonográficas. Adotando uma perspectiva sociológica da vida econômica, particularmente uma abordagem político-cultural dos mercados, buscase demonstrar que as relações de poder que formam o mercado de discos físicos se reproduzem no mercado fonográfico digital. A hipótese é que os catálogos de música manejados pelas empresas eletrônicas são o fator fundamental de diferenciação entre si e de produção das relações de poder no mercado digital. A análise dos dados obtidos nesta pesquisa leva à conclusão de que a partilha desigual dos catálogos entre empresas eletrônicas configura uma concentração da distribuição dos fonogramas digitais sem que haja uma centralização da produção fonográfica, caracterizando uma situação de concentração sem centralização.

\section{Uma interpretação político-cultural da destruição criadora da indústria fonográfica no século XXI}

Nesta pesquisa, adotou-se como referência teórica a sociologia econômica, precisamente o que se pode classificar de abordagem político-cultural dos mercados (political-cultural approach) (Fligstein, 2001). Trata-se de entender que a ação social econômica (Weber, 1999), isto é, aquela ação que visa fins econômicos sendo condicionada pela ação dos 
outros agentes que ocupam o mercado, ocorre em "campos" (Bourdieu, 2005), espaços sociais no qual há concorrência entre agentes sociais em torno de interesses específicos, os quais se organizam em torno de agentes com capitais (econômicos e/ou simbólicos) distribuídos de forma desigual e que buscam impor sistemas de dominação, quer dizer, suas concepções e interesses aos demais atores.

Nessa perspectiva, entende-se que, na medida em que interagem, os agentes econômicos passam de uma competição acirrada entre si à estabilidade das relações de troca. Isto lhes permite interpretar as condições do mercado e, assim, delinearem suas estratégias baseando-se no pré-entendimento que constroem de seus concorrentes e clientes. A repetição sistemática das relações de troca acarreta o desenvolvimento de uma cultura local do mercado, uma teia de significados que gera enquadramentos interpretativos os quais norteiam a identidade e as possibilidades de ação para os atores sociais em um determinado mercado (Fligstein, 2001). Isso significa dizer que a cultura local estabelece posições assimétricas entre os agentes sociais (dominantes e dominados), os quais buscam reproduzi-las ao longo do tempo. A continuidade das relações de troca engendra distintas instituições, as quais regulam as relações econômicas e mediam as disputas de poder entre os agentes sociais. Por instituição, entende-se não apenas as "[...] regras, procedimentos ou normas formais, mas também os sistemas de símbolos, os esquemas cognitivos e os modelos morais que fornecem 'padrões de significação' que guiam a ação humana" (Hall; Taylor, 2003, p. 19).

A abordagem político-cultural apresenta um enquadramento teórico que busca conciliar os aspectos estruturais à percepção dos agentes econômicos, caracterizando uma vertente das teorias de estruturação dedicada a explicar a formação e o funcionamento dos mercados modernos. Contudo, falta-lhe uma teorização da transformação dos mercados por fatores endógenos. Em outras palavras, o que provoca a mudança sistemática de um mercado? Como os agentes sociais respondem a elas? É 
evidente que diversos sociólogos e economistas políticos oferecem respostas distintas a essa questão. Neste artigo, porém, sustenta-se que a teoria da destruição criadora pode ser útil para explicar o fenômeno da transformação econômica.

O economista Joseph A. Schumpeter destacou-se por defender que o capitalismo era um sistema econômico dinâmico que evoluía através da introdução do que chamava de inovação ${ }^{2}$ por agentes empreendedores. De acordo com seu raciocínio, a inovação provocaria a ruptura do que chamava de fluxo circular de uma economia, ou seja, estado em que há uma relação harmônica entre demanda e oferta, acarretando uma reformulação completa das práticas de produção, circulação e consumo de bens e serviços, fenômeno que classificou tardiamente de destruição criadora (creative destruction) (Schumpeter, 2010). Schumpeter acreditava que a motivação dos empreendedores era desarticular o estado de forças estabelecido em um determinado mercado a fim de que pudessem assumir uma posição privilegiada em uma nova etapa de um comércio.

Embora recentemente parte de sua teoria tenha sido retomada para se pensar a relação entre inovação tecnológica e crescimento econômico, pouca atenção foi dada para a dimensão política da teoria da destruição criadora. Uma leitura sociológica de seus escritos revela, de fato, uma interessante teoria política da organização dos mercados. É possível entender que um mercado em fluxo circular seria equivalente a um mercado-como-campo, no qual se estabelece entre os agentes econômicos uma clara hierarquização de forças entre os agentes, o que garante a estabilidade das relações de troca. No entanto, buscando reverter a situação a seu favor, determinados agentes (empreendedores) introduzem inovações que desregulam as práticas correntes do mercado e estabelecem uma nova ordem nesse comércio. Nessa outra composição de forças, os empreendedores se sobressaem.

A inovação torna-se, assim, um instrumento de disputa política entre os agentes que compõem um mercado. Ela dá início a uma disputa por poder que é mediada 
pelas instituições desse mercado. Assim, a destruição criadora deve ser lida não como um período de experimentação aleatória em que determinadas inovações se mostram mais eficientes do que outras, mas como um processo de luta entre diferentes agentes sociais pela imposição de sistemas de dominação, mediada por instituições (o Estado, legislações, etc.).

A recente destruição criadora da indústria fonográfica pode ser lida nessa perspectiva. Ao longo do século $X X$, a fonografia se tornou um negócio de produção em larga escala de gravações sonoras em diferentes suportes físicos, a serem distribuídos para a venda no varejo. Nesse sistema, determinado tipo de empresa sobressaiuse: a gravadora. Entre si, dividiam-se entre grandes gravadoras (corporações de comunicação e entretenimento) e gravadoras independentes (médias e pequenas empresas fonográficas), diferença que se baseava em termos de poder econômico das empresas, traduzido na capacidade tecnológica para a produção e distribuição dos discos. Com a digitalização dos canais de distribuição dos bens culturais, porém, a função de mediação entre produtores e consumidores passou das gravadoras para empreendimentos típicos do entorno digital, as empresas eletrônicas ${ }^{3}$. Inovando nas formas de comercializar produtos e serviços, tornam-se os novos intermediários da indústria fonográfica nas redes digitais (De Marchi; Albornoz; Herschmann, 2011). Isto gera intensas disputas de poder nesse mercado. A seguir, apresenta-se um estudo de caso a fim de se compreender como este processo se desenvolve em um determinado contexto, neste caso, o brasileiro.

\section{Destruição criadora do mercado fonográfico brasileiro}

O início da recente destruição criadora da indústria fonográfica brasileira remonta à década de 90. Então, as grandes gravadoras decidiram adotar medidas visando diminuir seus custos de produção, sendo as mais destacadas a adoção do disco digital compacto 
(CD) como único produto dessa indústria e a terceirização dos sistemas de produção e distribuição de discos. Isso resultou na descentralização da produção fonográfica, com o surgimento de novas gravadoras nacionais independentes. Enquanto as grandes gravadoras investiam em grandes estrelas, as independentes passaram a revelar músicos e a dar continuidade às carreiras de artistas consagrados (De Marchi, 2006; Vicente, 2006). Com isso, as grandes gravadoras puderam se concentrar na distribuição dos produtos físicos em escala nacional, enquanto as independentes atuavam em escala local. Criava-se, assim, uma situação de descentralização da produção de fonogramas que era acompanhada da centralização da distribuição nas grandes gravadoras (Negus, 1999), organização característica do modelo de acumulação flexível ${ }^{4}$ (Harrison, 1997). Esse arranjo produtivo foi decisivo para alavancar o crescimento do mercado de discos físicos naquele período: entre 1990 e 1999, a venda de discos físicos cresceu 114,38\%, (De Marchi, 2011).

Na década de 2000, porém, foi possível perceber que tais mudanças também desencadearam transformações mais profundas. Isso se tornou visível no decréscimo da venda de discos e da arrecadação das gravadoras. Na Figura 1, apresentam-se os dados sobre a venda total de produtos físicos (áudio e vídeo) e a arrecadação de grandes empresas do setor entre 1999 e 2009:

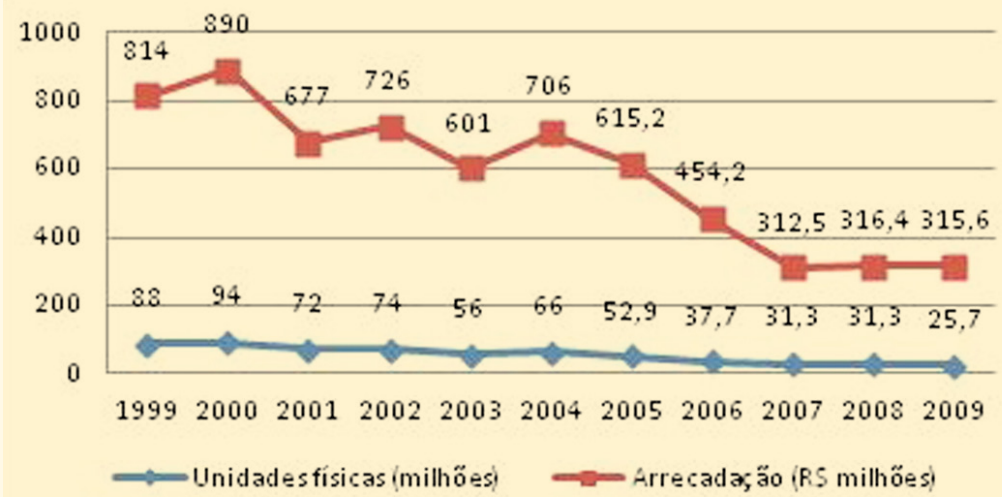

Figura 1 
Ao se tomar a venda de unidades físicas como parâmetro, e 2000 como ano base, pode-se notar uma queda de 23,4\%, entre 2000 e 2001, com leve recuperação de 2,77\% entre 2001 e 2002. Nos dois anos seguintes, há uma diminuição de 24,3\%, mas um incomum aumento de 18\%, em 2004. A partir de 2005, a retração segue até 2008 para, em 2009, voltar a cair 17,89\%. Entre os anos de 2000 e 2009, portanto, verifica-se uma diminuição de $72,66 \%$ na venda de discos físicos.

Representantes da indústria fonográfica insistiram em que essa forte retração de seu mercado resultava sobremaneira do consumo de produtos falsificados ou piratas. No entanto, tal argumento desconsiderava outros importantes fatores, entre eles, o consumo de fonogramas através de tecnologias digitais da comunicação. Ainda que os números oficiais não sejam de todo confiáveis, as atividades comerciais relacionadas à música nas redes digitais vêm crescendo ano a ano. Os negócios com fonogramas digitais no país cresceram 30\% em 2010 e já representam 17\% das movimentações da indústria doméstica, arrecadando cerca de 38,1 milhões de dólares naquele ano (IFPI, 2011). De acordo com a Federação Internacional da Indústria Fonográfica (IFPI, 2012), o mercado brasileiro de fonogramas digitais é um dos mais lucrativos da América Latina (junto ao mexicano e ao argentino, representa $86 \%$ do mercado digital de música nesse continente).

Tais dados demonstram que o consumo de fonogramas já não mais se resume à compra de discos físicos em lojas revendedoras. Pelo contrário, há indicações de que o consumo de fonogramas digitais começa a ser uma via importante entre os consumidores brasileiros, tornando as redes digitais em um lugar estratégico para a indústria fonográfica local. Resta entender como se estrutura esse emergente mercado. 


\section{A organização da indústria fonográfica brasileira nas redes digitais: concentração sem centralização das empresas eletrônicas fonográficas}

$\mathrm{Na}$ década de 2000, o mercado de fonogramas digitais no Brasil se dividia entre a venda de produtos e serviços via telefonia celular (MP3, chamadas de telefonia, ringback tones etc.) e pela internet. De acordo com os dados da Associação Brasileira de Produtores de Discos (ABPD), a telefonia celular correspondia à maior parte dos ingressos das atividades digitais (De Marchi, 2011). Essas atividades eram controladas ou por produtoras de celular, como a sueca Nokia (Nokia Music Service), ou pelas operadoras de celular locais, Oi, Claro, TIM e Vivo. Os serviços da internet eram prestados por empresas locais, em geral criadas por empreendedores locais não vinculados às tradicionais gravadoras. Um olhar atento a todas essas empresas revela importantes diferenças entre si no que diz respeito à oferta de produtos e serviços. $\mathrm{Na}$ pesquisa realizada para este artigo, buscou-se identificar e analisar os principais fatores que diferenciavam as empresas eletrônicas e seus efeitos sobre a organização do mercado digital de fonogramas ${ }^{5}$.

À primeira vista, o aspecto tecnológico se apresentava como provável vetor determinante das características dessas empresas. Afinal, um dos fatores de diferenciação entre grandes gravadoras e gravadoras independentes era a capacidade técnica de produzir discos em larga escala e distribuí-los ao longo de determinado território. No entanto, a observação e comparação das ferramentas utilizadas pelas empresas eletrônicas não permite chegar a qualquer conclusão. Por exemplo, tanto grandes companhias quanto microempresas nacionais utilizam as mesmas redes sociais na internet para se comunicarem com seus clientes (Youtube, Facebook, Twitter). Em alguns casos, as pequenas empresas desenvolveram estratégias de descentralização da venda de seus produtos e serviços que podem ser consideradas mais sofisticadas do que aquelas empregadas por grandes 
corporações, as quais restringiam à venda de poucos produtos em suas páginas na internet.

No entanto, o quadro mudava sensivelmente aos se compararem os catálogos oferecidos. Como são prestadoras de serviços, o poder de dispor de determinados conteúdos digitais torna-se vital para que possam atrair clientes. Um catálogo valioso (isto é, aqueles compostos por artistas populares e por composições de êxito comercial) pode expandir os horizontes de uma empresa, uma vez que lhe permite atrair clientes que lhes possibilitem atuar não apenas na internet como também via telefonia celular e/ou televisão digital. Todavia, o controle dos catálogos depende da capacidade de cada empresa negociar com os tradicionais agentes da indústria fonográfica. É nesse aspecto que se notaram as principais diferenciações entre empresas.

Em um universo de 150 páginas na internet relacionadas à música, apenas 8\% eram de empresas que dispunham dos catálogos das grandes gravadoras, enquanto $33,33 \%$ correspondiam a empresas que trabalhavam apenas com artistas e gravadoras independentes e 58,67\% eram páginas de artistas sem contrato com qualquer tipo de gravadora. Tal observação permitiu elaborar três tipos-ideais de empresas eletrônicas:

1. Grandes intermediários: administram os catálogos de grandes gravadoras e gravadoras independentes, negociando-os tanto com consumidores primários (empresas de telefonia celular, portais de internet, empresas eletrônicas estrangeiras, rádios pela internet, etc.) quanto finais (indivíduos).

2. Pequenos e médios intermediários: trabalham com gravadoras independentes e artistas autônomos. Seu diferencial reside em funcionar como aglutinadores de artistas, o que atrai um número maior de consumidores para suas páginas na internet. 
3. Artistas autônomos: músicos que desenvolvem seus próprios canais de acesso direto ao seu grupo de aficionados para divulgar sua obra e/ou vender produtos e serviços.

Na prática, tais categorias não são excludentes. Pelo contrário, atuam em diferentes níveis do mercado, o que lhes possibilita inclusive estabelecer relações mais de cooperação do que competição. Entretanto, se analisada separadamente, a capacidade de formar mercados para cada tipo de intermediário varia enormemente. A análise de casos concretos aclarará esta afirmação.

Como exemplo de grande intermediário, pode-se tomar a empresa iMusica $^{6}$ (http://www.imusica.com.br/). Criada em 2000, ela foi a primeira empresa a realizar a distribuição e venda em linha de fonogramas digitais no país. A partir do momento em que passou a dispor dos catálogos de todas as grandes gravadoras e das principais empresas independentes nacionais, essa companhia passou a diversificar seus serviços e a atender a diferentes clientes. Além de ser revendedora de fonogramas, tornou-se também plataforma de distribuição de conteúdo digital para lojas internacionais como iTunes e Spotify, conversora de discos para formatos digitais, procuradora para conseguir autorização dos direitos autorais para distribuição digital, entre vários outros serviços. Com isso, passou a atender a gravadoras, editoras de música, agências de marketing, portais de internet e operadoras de telefonia celular. De acordo com as informações disponíveis em seu site, até 2010, a companhia servia a 19 empresas de telefonia móvel em 16 países, possuindo 278 milhões de usuários por telefones celulares e 10 milhões por internet e lidando com um catálogo de 20 mil gravadoras e 10 milhões de arquivos musicais licenciados. A figura abaixo permite visualizar a rede de negócios que essa empresa desenvolveu: 


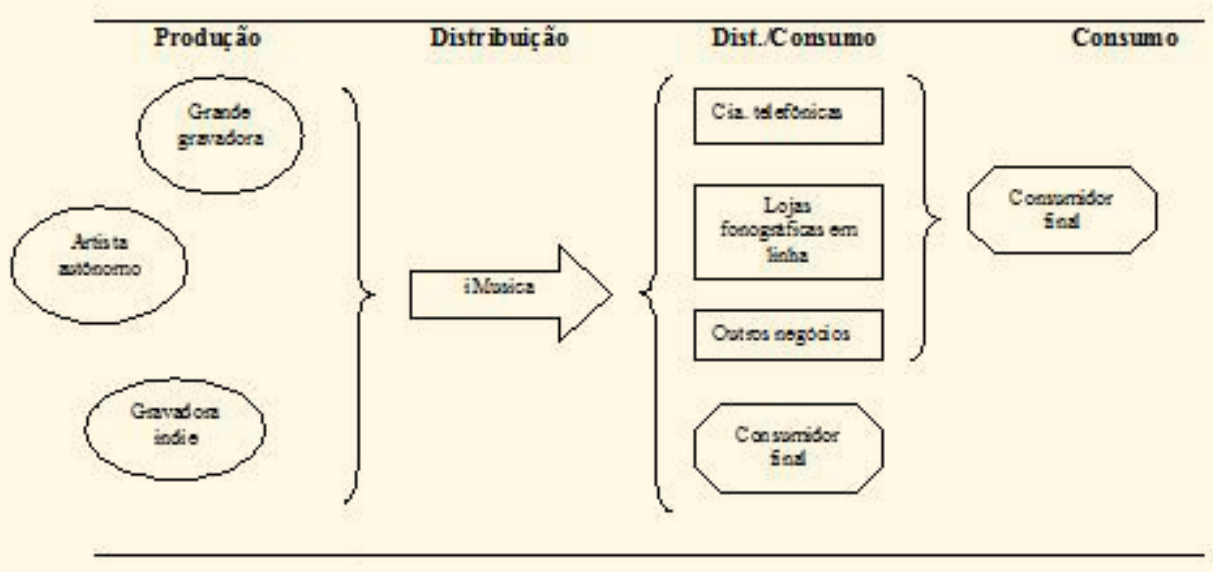

Figura 2

Pode-se notar que a companhia conseguiu desenvolver uma rede de consumidores primários que lhe permite ampliar ainda mais seu público final através das próprias empresas a que serve. Esta figura também destaca a posição privilegiada que a companhia ocupa no mercado de conteúdos digitais no Brasil, já que pode acessar todo tipo de consumidor através da internet e da telefonia móvel. De fato, ela era a única empresa eletrônica no país que trabalhava com todas as operadoras de celular na época desta pesquisa.

Perfil distinto apresenta um médio intermediário, como a companhia Trevo Digital ${ }^{7}$ (http://www.trevodigital.com.br/). Esta empresa trabalhava exclusivamente com 
artistas autônomos e gravadoras independentes nacionais. Como consequência, sua estratégia comercial limitava-se a vender fonogramas digitais na internet. A partir do pagamento de uma mensalidade por parte dos artistas contratantes, ela gerenciava e vendia os arquivos em MP3 através de sua página ou de um dispositivo que chamavam de loja portátil: uma conexão (janela) colocada na página virtual do artista, a qual levava o usuário diretamente ao sistema de vendas da empresa sem que deixasse a página em que estava. Além disto, possuía um serviço (Trevo Box) para uso das obras que administrava em comerciais, trilhas sonoras de televisão, cinema e publicidade entre outros. A seguinte figura representa a relação que a empresa mantinha com seus clientes:

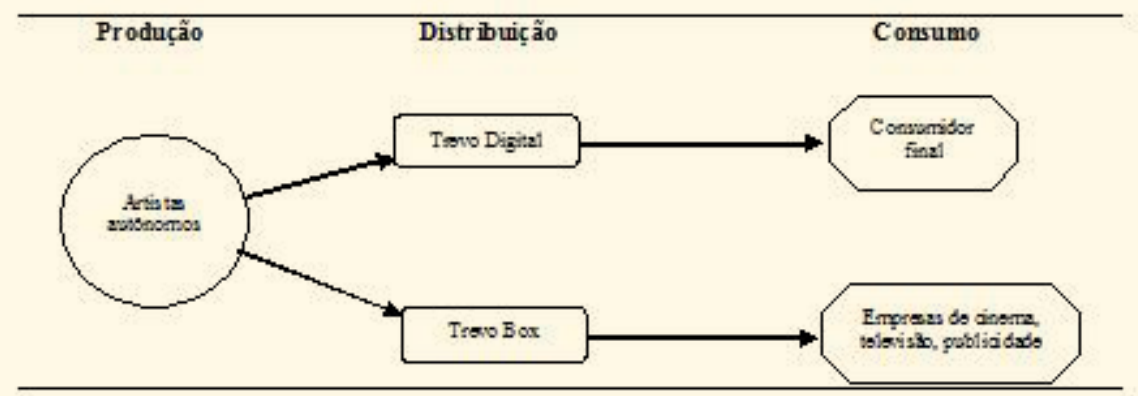

Figura 3 
A despeito de administrar uma quantidade considerável de conteúdos (havia 2000 músicas licenciadas de 200 artistas cadastrados, até fevereiro de 2010), o tipo de produto oferecido (obras de artistas autônomos) especializava sua clientela (fãs de artistas autônomos), diminuindo a probabilidade de atração de grandes clientes primários (empresas) e, portanto, de ampliação de suas atividades. Também é importante ressaltar que as redes de clientes de seus dois serviços não se entrecruzavam, restringindo o acesso da empresa a novos consumidores finais através dos primários. Um dos resultados disso era a ausência de atividade no lucrativo mercado de telefonia celular.

Há atualmente um número incomensurável de músicos que publicam suas obras na internet. Aproveitando-se da facilidade para gravar suas obras, esses artistas baseiam suas atividades comerciais nas apresentações ao vivo, utilizando a internet como plataforma de contato com os fãs e venda de produtos de merchandising. A observação dessas páginas na internet revela a repetição de algumas estratégias comerciais, o que permite tomar um exemplo como paradigmático desse fenômeno. Neste sentido, caso notório é do grupo Móveis Coloniais de Acaju ${ }^{8}$ (MCA).

A observação de seu site (http://www.moveiscoloniaisdeacaju.com.br/) demonstra que o MCA realiza seus projetos através de alianças estratégicas com outros agentes do entorno digital. Assim, vale-se das redes sociais, como Facebook, Twitter, Myspace e Youtube, para acessar seus fãs, utilizando seu site como nó articulador (hub) de suas ações na internet. Além disso, oferece acesso gratuito a seus fonogramas através da empresa eletrônica brasileira Trama Virtual. Através desses distintos meios de comunicação, o fã tem acesso a informações sobre a banda, a fonogramas para baixar, vídeos em linha, à agenda de concertos e a produtos de merchandising (camisetas, adesivos) ou Premium (CD, DVD) para comprar: 


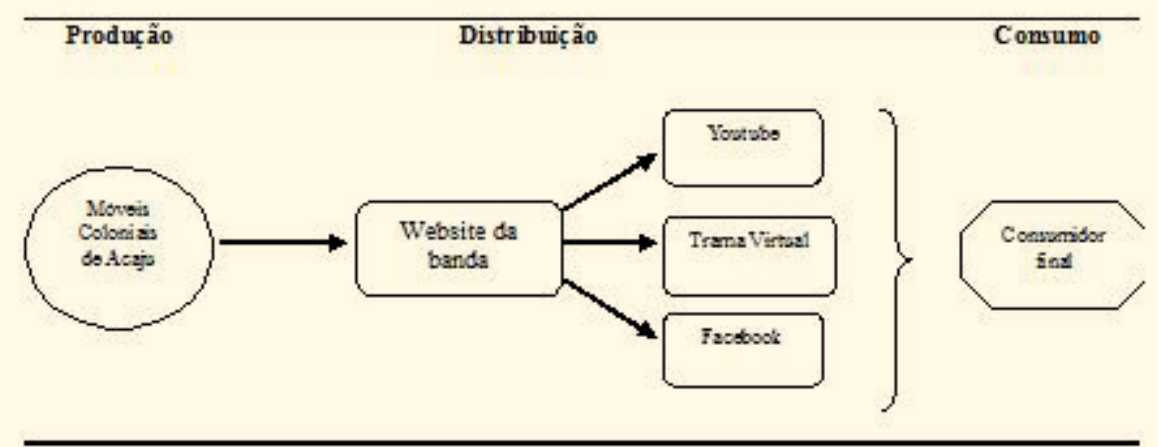

Figura 4

Tal descentralização da comunicação tem como principais objetivos ampliar o acesso aos fãs e dar visibilidade à marca da empresa (desde 2008, o MCA se tornou uma empresa formal). Isto lhe permite inclusive estabelecer parcerias pontuais com outras companhias ${ }^{9}$. Todavia, os produtos e serviços oferecidos por essa banda-empresa são ainda mais especializados do que as dos pequenos e médios intermediários. Limitada a diversidade dos produtos, torna-se difícil diversificar sua clientela a ponto de acessar novos consumidores através de outras plataformas (telefonia móvel ou televisão digital, por exemplo), prescindindo do auxílio de intermediários.

Os três casos apresentados confirmam que os catálogos manejados pelas empresas eletrônicas constituem um fator fundamental para seu funcionamento. São eles que lhes permitem (a) atrair distintos tipos de clientes, (b) criar diferentes serviços 
para (c) acessar novos consumidores (indivíduos e empresas) através de uma ou mais redes digitais (internet, telefonia celular, televisão a cabo ou digital). Enquanto artistas autônomos e pequenos intermediários tendem a atuar em uma mesma faixa de mercado, disputando entre si o mesmo nicho, os grandes distribuidores acessam os mercados nacional e internacional de música através de parcerias com outras empresas de internet ou telecomunicações. Isso lhes possibilita inovar em serviços e se adaptar melhor às mudanças do mercado. Logo, conclui-se que o poder de dispor dos catálogos acarreta certa gradação no acesso aos bens culturais e uma conseguinte divisão do trabalho entre empresas eletrônicas, definindo a posição que cada uma ocupa no emergente mercado digital.

O fenômeno da hierarquização das empresas eletrônicas revela que o poder dos tradicionais agentes da indústria fonográfica foi, em parte, restituído (sobremaneira, de). Através do controle dos direitos autorais das obras, gravadoras e editoras passam a impor os termos de concessão das obras a determinados agentes que cumpram com seus objetivos. A partir das decisões que tomam sobre com quais intermediários negociam, interferem no desenvolvimento do conjunto de empresas eletrônicas. A resultante divisão do trabalho entre empresas eletrônicas comprova que as relações de poder que organizam o mercado de discos físicos se reproduzem no mercado digital.

A análise dos casos também permite concluir que a organização do mercado de fonogramas digitais reproduz a situação de concentração sem centralização que caracterizou a indústria fonográfica brasileira nos anos 1990. A despeito da abundância de conteúdos disponíveis, resultante da descentralização total da produção, seu acesso passa a ser mediado por um grupo de empresas que consegue distribuí-los em diferentes escalas. De forma similar ao que ocorria entre as gravadoras, também entre os novos intermediários há aqueles que se restringem a nichos de mercados locais e outros poucos que acessam mercados amplos (nacional e internacional). A 
estes é concedido um poder simbólico e econômico que lhes coloca, desde logo, como os agentes dominantes desse campo na percepção de artistas, gravadoras e outras empresas eletrônicas. Aos outros, resta-lhes uma posição precária de exploração de nichos restritos com um grau bastante reduzido de possibilidade de inovação na oferta de serviços. Assim, reproduz-se a cultura local do mercado de discos fiscos, deixando claro quais são as possibilidades de ascensão ou não nesse novo negócio.

\section{Considerações finais}

Seria imprudente fazer afirmações sobre os efeitos dessa concentração sem centralização, isto é, se ela criará barreiras à difusão de diferentes gêneros musicais e artistas no país. Esse ainda é um processo em andamento, aberto a reviravoltas. No entanto, as conclusões apresentadas nesta pesquisa permitem tecer importantes considerações sobre o mercado fonográfico nas redes digitais.

Em primeiro lugar, os dados apresentados permitem afirmar que estavam equivocadas as teorias que celebravam as redes digitais como um livre-mercado de bens culturais. Ao contrário do que se acreditava, o regime de direitos autorais tem sido capaz de criar gradações no acesso aos conteúdos digitais. O emergente mercado fonográfico digital se desenvolve não a partir da abundância e ubiquidade de fonogramas, mas de disputas pelo poder de controlar e dispor de valiosos conteúdos. E a divisão do trabalho entre empresas eletrônicas revela a reprodução de relações de poder que caracterizavam o mercado de discos físicos. Isso não significa dizer que a divisão entre empresas eletrônicas de fonogramas se dê conforme a dicotomia entre grandes gravadoras versus gravadoras independentes. Há um grande número de prestadores de serviços para as empresas eletrônicas que constituem esse emergente mercado e que tornam mais complexas as relações de poder entre esses novos agentes 
da indústria fonográfica. No entanto, é possível identificar a constituição de relações de poder a partir do acesso aos catálogos de gravadoras e editoras, o que lhes restitui certa capacidade de influir no desenvolvimento do mercado digital.

Este dado é fundamental para se pensar o futuro da indústria da música. A gradação do acesso aos bens culturais e a divisão do trabalho entre as empresas eletrônicas sugere que a capacidade de ação dos empreendedores passa a ser restringida. De uma competição acirrada por novas oportunidades econômicas, o mercado digital de fonogramas começa a apresentar claras fronteiras aos empreendedores para o desenvolvimento de seus negócios. Já é evidente com quem se deve negociar para acessar diferentes mercados e como se deve fazê-lo. Cabe observar, a partir de agora, como isso pode afetar a circulação de música nas redes digitais no país.

\section{REFERÊNCIAS}

BOURDIEU, Pierre. The social structures of the economy. Londres: Polity, 2005.

CASTELLS, Manuel. A galáxia da Internet: reflexões sobre a Internet, os negócios e a sociedade. Rio de Janeiro: Jorge Zahar Editor, 2003.

DE MARCHI, Leonardo. Indústria Fonográfica e a Nova Produção Independente: o Futuro da Música Brasileira? Comunicação, Mídia e Consumo, São Paulo, v. 3, pp. 167-182, 2006.

DE MARCHI, Leonardo. Transformações estruturais da indústria fonográfica no Brasil 1999-2009: Desestruturação do mercado de discos, novas mediações do comércio de fonogramas digitais e consequências para a diversidade cultural no mercado de música. 2011. 289 p. Tese (Doutorado em Comunicação e Cultura) Escola de Comunicação da Universidade Federal do Rio de Janeiro, Rio de Janeiro, 2011.

DE MARCHI, Leonardo; ALBORNOZ, Luis A.; HERSCHMANN, Micael. Novos negócios fonográficos no Brasil e a intermediação do mercado digital de música. Revista Famecos, Porto Alegre, v. 18, n. 1, pp. 279-291, jan.-abr. 2011.

FLIGSTEIN, Neil. The architecture of markets: an economic sociology of twenty-first century capitalist societies. Nova York: Princeton University Press, 2001.

HALL, Peter A.; TAYLOR, Rosemary C. R. Três versões do neo-institucionalismo. Lua Nova, n. 58, pp. 193-223, 2003. 
HARRISON, Bennett. Lean and mean: why large corporations will continue to dominate the global economy. 2. ed. Nova York: The Guilford Press, 1997.

HERSCHMANN, Micael. Indústria da música em transição. São Paulo: Estação das Letras e Cores, 2010.

INTERNATIONAL FEDERATION OF THE PHONOGRAPHIC INDUSTRY. Record industry in numbers 2011. Londres: IFPI, 2011.

. Digital music report 2012. Londres: IFPI, 2012.

LEONHARD, Gerd; KUSEK, David. The Future of Music. São Francisco: Berkley Press, 2009.

NEGUS, Keith. Music genres and corporate cultures. Londres: Routledge, 1999.

SCHUMPETER, Joseph A. A teoria do desenvolvimento econômico. São Paulo: Abril Cultural, 1982.

. Capitalism, socialism and democracy. Londres: Routledge, 2010.

VICENTE, Eduardo. A vez dos independentes(?): um olhar sobre a produção musical independente do país. E-Compós, Brasília, 2006.

WEBER, Max. Economia e sociedade. Brasília: Editora UnB, 1999.

YÚDICE, George. Nuevas tecnologías, música y experiencia. Barcelona: Gedisa, 2007.

\section{NOTAS}

1 Uma versão inicial deste artigo foi apresentada no XX Encontro da Compós, em junho de 2011. Este trabalho resulta da pesquisa apresentada na tese "Transformações estruturais da indústria fonográfica no Brasil 1999-2009", defendida no Programa de Pós-Graduação da Escola de Comunicação da Universidade Federal do Rio de Janeiro, contando com o apoio do CNPq, através da bolsa de doutorado no Brasil, e da CAPES, através da bolsa do Programa de Doutorado no País com Estágio no Exterior, e premiada pelo Ministério da Cultural do Brasil no I Prêmio Economia Criativa - Estudos e Pesquisas, em 2012.

2 Por inovação entenda-se "novas combinações" que destoam das práticas habituais de produção, distribuição, compra e venda de bens e serviços, podendo englobar diferentes fenômenos, tais quais: a introdução de um novo bem ou um novo método de produção, a abertura de um novo mercado, o estabelecimento de uma nova organização de qualquer indústria, entre outras possibilidades. Schumpeter, 1982.

3 Adota-se a definição de Manuel Castells (2003, p. 57): "por empresas eletrônicas entendo qualquer atividade de negócio cujas operações-chave de administração, financiamento, inovação, produção, distribuição, vendas, relações com empregados e relações com clientes tenham lugar predominantemente pela/na internet ou outras redes de computadores, seja qual for o tipo de conexão entre as dimensões virtuais e físicas da firma". 
4 Esta expressão foi cunhada por Bennett Harrison (1997) em seu debate com os teóricos da acumulação flexível. Harrison demonstrou que, a despeito do crescimento das redes de pequenas e médias empresas, apenas as grandes corporações multinacionais possuíam capital econômico e político para promover a circulação de seus produtos em escala planetária. Assim, desenvolvia-se uma concentração da distribuição dos produtos, sem que houvesse a centralização da produção de bens.

5 A pesquisa realizada entre fevereiro de 2009 e fevereiro de 2010 baseou-se na análise de 150 páginas na internet de artistas, grandes gravadoras, gravadoras independentes e diferentes empresas eletrônicas relacionadas ao acesso a fonogramas no Brasil. Os critérios de avaliação dessas páginas na internet foram: (a) a quantidade e a natureza dos serviços e produtos oferecidos, (b) catálogos oferecidos, (c) clientes das páginas (se apenas indivíduos ou também empresas e, neste caso, de que natureza).

6 Sediada na cidade do Rio de Janeiro, a iMusica faz parte da holding Ideiasnet S.A., companhia que desenvolve projetos e adquire participações em companhias do setor tecnologia, mídia e telecomunicações.

7 Fundada em 2007 por dois músicos com a intenção de distribuir as obras de sua própria banda e de bandas de conhecidos. Em 2012, a empresa encerrou suas atividades.

8 Móveis Coloniais de Acaju é uma banda de pop-rock, formada em 1998, na cidade de Brasília (DF). Sem nunca ter assinado com uma gravadora, o grupo possui três álbuns de estúdio lançados e DVD de suas apresentações ao vivo.

9 Recentemente, a banda-empresa estabeleceu em parceria com empresas. Associou-se à empresa de produtos alimentícios, Sadia, para realizar o vídeo "Dois sorrisos", exposto no YouTube. Depois, em parceria foi com o canal de televisão MTV Brasil, realizou do videoclipe "O tempo".

Recebido em: 06 jul. 2013

Aceito em: 05 mar. 2014

\section{Endereço do autor:}

Leonardo de Marchi <leonardodemarchi@gmail.com>

Universidade de São Paulo, Escola de Comunicações e Artes.

Av. Prof. Lúcio Martins Rodrigues, 443, bloco 4

Cidade Universitária

05508-020 São Paulo, SP, Brasil 